\title{
DEVELOPING A NEW PROJECT EVALUATION SYSTEMS BASED ON KNOWLEDGE
}

\author{
Tadeusz A. GRZESZCZYK
}

Faculty of Management, Warsaw University of Technology, Warsaw, Poland

e-mail: t.grzeszczyk@wz.pw.edu.pl

\begin{abstract}
The article is dedicated to the modelling of a new project evaluation systems based on knowledge. Author suggests possible direction of project evaluation systems development. This enabled the application of data mining algorithms for discovering patterns in data sets. The concept of a new evaluation system based on knowledge is synthetically discussed. The example of using association rule base for analysis of project stakeholders surveys is also presented.
\end{abstract}

Keywords: project evaluation systems, systems based on knowledge, modelling of a new project evaluation systems, stakeholders analysis, association rules.

\section{Introduction}

The ability of creating new knowledge and using it in the process of projects realisation plays an important role in the process of solving multifaceted problems in global and turbulent contextual environment of organisations. In modern enterprises projects mostly decide based on obtained results. Not only they support a continuous improvement of core processes but also contribute to making a transformational change on a strategic level ${ }^{1}$.

Multidimensional and comprehensive project evaluation is increasingly important nowadays ${ }^{2}$. Depending on the type of evaluation, it can be used to make different decisions. They may concern, e.g. selection of projects for implementation, continuation of its realisation or summary of the results achieved at the end of the project. The evaluation process is characterised by an interdisciplinary nature. This process requires conducting structuring evaluation approaches for collecting data, information and knowledge, which then must be analysed using interdisciplinary methods and systems ${ }^{3}$.

Systems based on knowledge should play an important part among interdisciplinary evaluation approaches. The process of project evaluation requires knowledge management. Knowledge is fundamental in the process of project management and evaluation. Proper management of knowledge about evaluation is intended to

\footnotetext{
1 Barrows E., Neely A. - Managing Performance in Turbulent Times: Analytics and Insight, John Wiley \& Sons, Hoboken, New Jersay 2012, p. 67.

${ }^{2}$ Grzeszczyk T.A. - Towards the Model of Comprehensive Project Evaluation System, Monographic Series of Faculty of Management, ed. T. Krupa, Warsaw University of Technology, Warsaw 2013.

${ }^{3}$ Grzeszczyk T.A. - Evaluation of European Projects 2007 2013, Placet, Warszawa 2009 (in polish)
}

increase knowledge about the evaluated current project, which can also be used in the implementation of other planned projects.

Appropriate project management knowledge and ability of improving that knowledge play key roles in achieving organisation's success ${ }^{4}$. Project management can be defined as a field that uses the available and specific knowledge and skills, methods and tools to harmonise the interaction of the project's participants in the process of project implementation, reaching its objectives in the assumed time, using available resources ${ }^{5}$.

Application of new knowledge-based technology in this field allows the implementation of computational systems for the analysis of complex, multi-faceted and multi-disciplinary, socio-economic evaluation of uncertainty problems. Research on knowledge-based methods make possible practical solutions in evaluation and require continuation in the context of the necessity of implementation of basic rules of knowledge management and knowledge-based economy. These researches should be carried out on micro- and macroeconomic levels. AI (Artificial Intelligence) approaches are modern implementation methods useful in a knowledge-based company, well functioning, in the information/knowledge age, an information society and digital economy.

\footnotetext{
${ }^{4}$ Love P., Fong P., Irani Z. (eds.) - Management of Knowledge in Project Environments, Routledge, 2005, pp. IX-X.

5 Trocki M., Bukłaha E., Grucza B. - Projects and Project Management [in] Knowledge Management in Projects. Methodologies, Models of Competence and Maturity Models, M. Trocki (ed.), Publishing House Warsaw School of Economics, Warsaw 2011 (in polish), pp. 53-54.
} 
Realisation of research on knowledge-based systems leads to the development of management sciences. Knowledge technologies can be used, e.g. in a multicriteria process of decision making relating to comprehensive project evaluation. A number of socioeconomic data of information and knowledge resulting from them is still increasing. It is not possible to realise a comprehensive evaluation process without the use of knowledge technologies and computer systems connected with them. Classical data processing applications are not useful in the case of large, complex, empirical and uncertain data sets.

An evident research gap can be noticed in project evaluation systems. Most evaluation systems which have been known until now concern one-aspect, quantitative and short-term evaluation of project operations. Most of systems adapted to a qualitative analysis of empirical data which come from people (e.g. project stakeholders) is insufficient.

The evaluation system should function in a multiaspect way. Pursuing to multi-aspectness is equivalent to noticing the need and possibility of building the model of a comprehensive evaluation system ${ }^{6}$. Such a system should take qualitative and quantitative conditions into account. For example, social, economical, environmental, technical, organisational, legal, ecological, cultural and political aspects can be itemised among qualitative aspects. It is important to consider factors such as difficult to measure, permanent and sustainable socio-economic development of regions and other in the process of evaluation of projects realisation in a turbulent environment.

One of the possible concepts of development of project evaluation systems toward complex solutions is integration of various evaluation methods. The author carry out research on possibilities and the need of integration of classical evaluation methods with methods which allow to discover and manage knowledge. Classical evaluation methods are better studied. Thus, there is a need to carry out research on new project evaluation methods and systems based on knowledge.

There is a research assumption that using modern concepts and methods which allow a knowledge discovery and management is an essential condition of correct functioning of the comprehensive evaluation system.

\footnotetext{
${ }^{6}$ Grzeszczyk T.A. - Towards the Model of Comprehensive Project Evaluation System [in] Monographic Series of Faculty of Management, ed. T. Krupa, Warsaw University of Technology, Warsaw 2013.
}

They can pose an essential complement for classical evaluation methods. In this paper the concept and example of a new evaluation knowledge-based system using selected data mining algorithms has been presented. The implementation of these systems enables well-informed and multiple-aspect decision-making, even in case of comprehensive and multifaceted projects in the global and turbulent environment.

\section{The essence of an evaluation process}

Evaluation plays bigger and bigger role in management sciences. In recent years, theoretical and practical scientific achievements concerning, i.e. improving organisation, management and evaluation of process quality has increased significantly. Many are subject to evaluation process. They are, e.g. project, programme, policy, strategy, process, system, initiative, action, product etc. In this study considerations concern the evaluation of a project or programme.

A project is a system of activities characterised by its parameters: scope, necessary resources (human, knowledge, capital, material, technological) and deadlines ${ }^{7}$. Projects can be assigned to specific programme or occur separately. A programme is a collection (set) of multiple interrelated projects carried out for the implementation of mutually reinforcing policy strategic objectives $^{8}$.

A worldwide respected association, the PMI (Project Management Institute) defines the programme as a 'set (group) of projects which are managed in an integrated and coordinated way'. Individual projects included in the programme are usually combined and relations between them can be identified ${ }^{9}$. Evaluations of policies, programs or projects are the judgement of their value, taking into account the earlier assumptions and criteria on the basis of collected information analysed for this purpose ${ }^{10}$.

\footnotetext{
${ }^{7}$ Kisielnicki J. - Project Management. People - Procedures Results. Oficyna Wolters Kluwer Business, Warsaw 2011 (in polish), p. 15.

${ }^{8}$ PMBOK Guide - A Guide to the Project Management Body of Knowledge, Fourth Edition. Management Training \& Development Center, Warszawa 2009, p. 10.

${ }^{9}$ Heldman K. - PMP. Project Management Professional Exam. Study guide. John Wiley \& Sons, Inc., Indianapolis 2011, p. 8.

10 MEANS Collection, Vol. 1 - Evaluating socio-economic programmes. Evaluation design and management, European Commission Structural Funds, Luxembourg 1999, p. 17.
} 


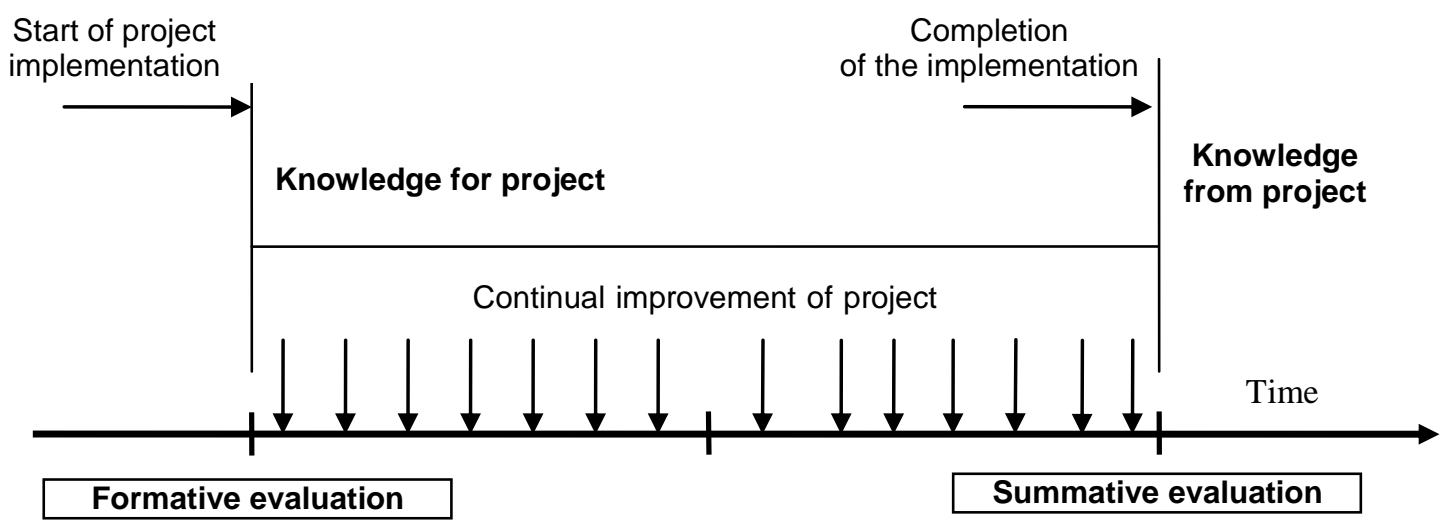

Figure 1. Types of evaluation and knowledge (source: own study)

An evaluation process should be implemented in an orderly and systematic way. The best-known definition of the evaluation has been formulated by M. Scriven. According to this definition evaluation is the systematic process. The aim of this process realisation is to achieve products in the form of the merit, worth or value of an object ${ }^{11}$.This systematic process should be realised on the basis of the required standards or criteria for judging the projects' performance ${ }^{12}$.

Evaluation research, which are carried out systematically, is useful not only in the case of the currently evaluated project and programme. M. Q. Patton paid attention to the fact that the results of systematically carried out evaluation research are often applied in the process of improving future projects and programs. Thus, it is necessary to collect information systematically about the activities and project results to make judgments about it. Not only does it enable to increase knowledge about the evaluated project but also favours improving further operations, developing project effectiveness and efficiency. It facilitates making up proper decisions about future programming ${ }^{13}$.

The project evaluation system should meet four basic principles: significant participations of stakeholders, impartiality and independence, credibility and transparency, usefulness - benefits from the results of the eval-

\footnotetext{
${ }^{11}$ Scriven M. - Evaluation thesaurus. Sage Publications, Inc., London 1991, p. 1.

${ }^{12}$ Rossi P. H., Lipsey M. W., Freeman H. E. - Evaluation A systematic approach, Thousand Oaks, Sage Publications, Inc., CA 2004, p. 16

${ }^{13}$ Patton M. Q. - Qualitative Research \& Evaluation Methods. Thousand Oaks, SAGE Publications, Inc., London, New Delhi 2002, p. 10.
}

uation report. There are many kinds of these systems. They can be classified in a different way. The most evident is a classification from the point of view of time. Evaluation may be carried out before project realisation (ex-ante evaluation). Evaluation during the project (ongoing evaluation) and after finishing the project (ex-post evaluation) is also known.

The popular one is also a classification of evaluation from the point of view of its execution objectives. They may be cognitive and instrumental objectives. In the case of cognitive objectives, it is about the increase of possessed knowledge about the evaluated project. Then evaluation results may be used to work on similar projects. In turn, executing evaluation with instrumental objectives makes it possible to use its results, e.g. in the process of making decisions about project implementation.

Two other kinds of evaluation associated with instrumental objectives are also known. The first one is summative evaluation and it is used to support decision making about a completed project. This type of evaluation enables supporting decision making about, e.g. organisational changes, modifications leading to improvement of financial and economic efficiency and effectiveness etc. The second one is formative evaluation. It is connected with ex-ante evaluation and ongoing evaluation. Formative evaluation helps to improve a project and make a decision about beginning, continuing or ending a project. Different kinds of knowledge are connected with the types of evaluation mentioned above (Figure 1). 
In the literature, various notions connected with knowledge management and project management are used. It can be, e.g. assumed that a superior role is played by all knowledge connected with projects planning and realisation. Knowledge from projects results from completed projects. Knowledge about project management concerns methods, techniques, tools and the best practises of project management. Knowledge in projects means possessed and desired sources of knowledge which are administered by project teams. Knowledge about projects is knowledge about a set of projects creating past, actual and future programs ${ }^{14}$.

According to the approach of D. Damm and M. Schindler, one should pay attention to considerations within the holistic view. In this view, three kinds of knowledge can be distinguished: about projects, in project and from projects. Knowledge about project results from skills management, measurement of controlling indicators, records of planning and control documents, projects marketing and designing of organisation structures. The sources of knowledge in projects are documentation, discussions effects, meeting repository and knowledge from information systems - PIM (Personal Information Manager), GIM (Geographic Information Management), etc. Knowledge from projects means learning from best practises/lessons learned ${ }^{15}$.

Similarly to classifications presented above a typology of evaluation can be presented. Evaluation knowledge is the most general term including total knowledge connected with project evaluation. Additionally, following kinds of knowledge connected with project evaluation can be distinguished. Knowledge about project evaluation is equivalent to meta-evaluation, which is assessment of evaluation process. Knowledge from project evaluation results from realisation of evaluation process. Knowledge in the project evaluation process concerns systems, methods and techniques of conducting project evaluation processes ${ }^{16}$.

In the project evaluation process the following things should be identified: key research questions, the meth-

\footnotetext{
${ }^{14}$ Wyrozębski P. and others - Study of Project Knowledge Management Practices in Polish Organizations [in] Knowledge, Maturity and Risk in Project Management. Publishing House, Warsaw School of Economics, Warsaw 2012 (in polish), p. 55.

15 Damm D., Schindler M. - Security Issues of a Knowledge Medium for Distributed Project Work [in] International Journal of Project Management, 20(2002), p. 40.

${ }^{16}$ Grzeszczyk T.A. - Modeling Evaluation of European Projects. Placet, Warszawa 2012 (in polish).
}

odological strategies for answering these questions, criteria and indicators for project evaluation, research methods associated with various stages of the evaluation process and creating a system of methods for comprehensive evaluation project. The basic set of evaluation criteria including efficiency, effectiveness, relevance, sustainability and impact. These criteria are concretized for certain projects. They refer to social, economic, environmental, scientific, technological and other aspects. Thus, they have interdisciplinary and multidimensional character. Their proper consideration in evaluation research is possible to provide that modern ICT technologies are used. New methods based on knowledge should play an important part in evaluation methods.

\section{Evaluation systems based on knowledge}

In the introduction of this paper, research assumption is made that the essential condition of correct functioning of the comprehensive evaluation system is the application of modern concepts and methods which allow knowledge management. These new approaches to project evaluation can be a complement of classical evaluation methods within the multi-faceted hybrid system of methods (Figure 2). Development of new project evaluation methods based on knowledge should proceed simultaneously with research on classical evaluation methods.

Due to the dynamic development of ICT technology, it is quite easy to design and build information systems gathering knowledge, learning and supporting knowledge management. Such systems can learn, adapt and improve themselves, thanks to gained knowledge from empirical data which are learning examples. It is possible to discover knowledge and save it in knowledge bases which are the basic element of KBS (Knowledge-Based Systems). KBS are usually based on AI, machine learning and data mining methods. Among popular data mining methods, e.g. decision trees, neural networks ${ }^{17}$, genetic algorithms, fuzzy logic, rough set ${ }^{18}$, case-based reasoning, intelligent agents,

\footnotetext{
${ }^{17}$ Grzeszczyk T.A. - Application of Neural Networks for Prior Appraisal of Structural Funds Project Proposals [in] Seruca I., Filipe J., Hammoudi S., Cordeiro J. (ed.) - Enterprise Information Systems, Vol. 2., Portucalense University, Porto, Portugal 2004

${ }^{18}$ Grzeszczyk T.A. - Application of the Rough Set Method for Evaluation of Structural Funds Projects [in] Manolopoulos Y., Filipe J., Constantopoulos P., Cordeiro J. (ed.) - Artificial Intelligence and Decision Support Systems. Paphos, Cyprus 2006.
} 


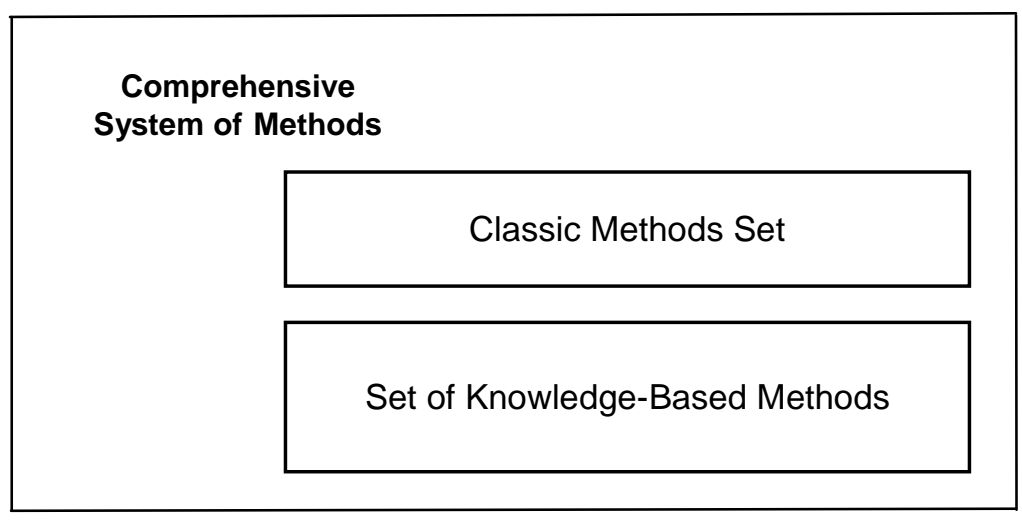

Figure 2. The multi-faceted hybrid system of methods (source: [7], p. 93)

if-then-else rules, association rules can be listed.KBS and so called intelligent systems function on the basis of a different type of knowledge: static and dynamic. The static knowledge refers to facts describing certain reality. It is so called declarative knowledge (aka descriptive knowledge, propositional knowledge). This dynamic knowledge enables to describe dynamics of occurring processes and it is procedural knowledge (aka imperative knowledge).

According to B. Stefanowicz, in the world of AI methods, three elements reflect procedural knowledge: algorithms, heuristics and analogies. These elements together with declarative knowledge create a basis for building a consistent model where the surrounding universe was best described ${ }^{19}$.

Knowledge can be stored in two forms: symbolic and non-symbolic. The symbolic form is usually used in knowledge-oriented systems. Knowledge is recorded there in the form of a certain kind of symbols which are understood in a specific way. An ordinary alphabet can be one of the symbols. Knowledge is then recorded by means of sentences readable to people. Thanks to this, such knowledge may be not only processed by computers in the process of machine learning but also read out and processed by people. The most known AI methods use symbolic knowledge in the following forms: association rules, decision rules, decision trees, lists, knowledge frames, semantic networks and objectattribute-value triplets.

The associations rule is one of several more known methods of data mining. This method is used to discover hidden patterns and potentially useful relations between variables in usually empirical data. Decision

\footnotetext{
${ }^{19}$ Stefanowicz B. - Algorithms. Heuristics. Analogies [in] Statistical News, 3/2012 (in polish), p. 77.
}

rules are a symbolic representation of behaviour and knowledge of human experts. Decision trees apply to present the sequence of interrelated decisions and the expected results resulting from them. These results come out from choosing a certain way of acting. Changes of made decisions lead to the modification of decision trees ${ }^{20}$.

A crucial feature of symbolic knowledge representation methods is processing knowledge in a qualitative form. The way of representing knowledge usually enables relatively easy realisation of an interactive dialogue with the user of this kind of systems. The result of such a dialogue are offers of system concerning solving desirable problems, offers necessary to make decisions, etc. What is more important, this advice and suggested decisions may be, in a relatively simple way, justified. Yet, knowledge is recorded in a knowledge base in a symbolic form which is understood for the system user.

The most known way of saving knowledge in a readable and understood form for human is decision rules in the structure of 'if-then'. Quantitative and qualitative knowledge gained from experts evaluating projects is transformed to the form which enables its saving, processing and using ${ }^{21}$. This knowledge can be discovered also from data resulting from surveys conducted among project stakeholders.

Knowledge that is stored in the if-then rules can be of an important significance in the processes. Project management is often gamed through experiential learning. These rules are pieces of knowledge about project

\footnotetext{
${ }^{20}$ Heldman K. - PMP. Project Management Professional Exam. Study guide. John Wiley \& Sons, Inc., Indianapolis 2011, pp. 265-266.

${ }^{21}$ Grzeszczyk T.A. - Modeling Evaluation of European Projects. Placet, Warszawa 2012 (in polish).
} 
management and evaluation. Rules of thumb (heuristics) can be in the form of anecdotes, best practises, lessons learned, experimental rules, guidelines, cases etc. ${ }^{22}$ Machine learning and data mining methods allow to obtain such rules through the use of computer systems.

Machine learning methods enable to formulate algorithms useful for discovering knowledge saved in the knowledge base built from induced decision rules received from expert knowledge. Learning examples are projects evaluated before. Decision rules are induced when using one of selected algorithms of machine learning. Generally, using machine learning system consists in inducing decision rules and looking for such rules which enable classification.

Decision rules are generated from examples, so called learning objects of known classifications. These rules are induced in order to use them to classify new objects. In the case of associations' rules, the process of discovering knowledge happens without learning examples. The associations rule has the following conditional form (if A then B): A $\rightarrow$ B. A sentence implies $B$ sentence. Sentence is a set of attributes.

Thanks to the use of associations' rules, it is possible to discover knowledge which is not accessible directly. Knowledge discovery means quantitative and qualitative analysis. The qualitative analysis which consists in finding relationships, correlations, patterns and useful knowledge in an analysed data sets is particularly important. Significant usefulness of this kind of solutions results from the possibility of relatively easy implementation of the evaluation system based on knowledge on the basis of a defined concept.

\section{Concept of a new evaluation system based on knowledge}

Resources necessary for planning and implementation of projects are becoming more difficult to reach. So, it is important to make reasonable distribution of resources, which are allocated for projects execution. We can see an arising problem in evaluating projects in a proper way. An important assumption is for the projects to solve certain problems consistent with stakeholders' needs and expectations. Project objec-

\footnotetext{
${ }^{22}$ Liebowitz J. - Conceptualizing and implementing knowledge management [in] Love P., Fong P., Irani Z. (eds.) - Management of Knowledge in Project Environments. Routledge, 2005, p. 5.
}

tives, evaluation indicators and criteria ought to be formulated in consultation with stakeholders.

Therefore, surveying opinions of project stakeholders is very significant in the process of evaluation. No matter what evaluation method was chosen, stakeholders analysis should not be ignored. This analysis can be carried out as an independent evaluation tool or as a part of complex evaluation methods. For example, stakeholder analysis is the first step in Analysis phase and Problem analysis ${ }^{23}$ which were performed in accordance with the Logical Framework Approach (Figure 3).

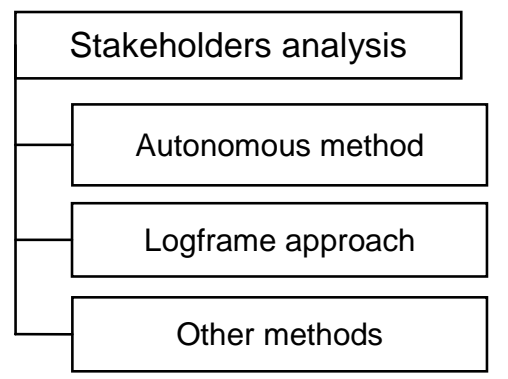

Figure 3. The importance of stakeholders analysis in project evaluation systems (source: own study)

In evaluation systems, except classical approaches, new methods should be researched. According to increasing uncertainty, unpredictability and irregularity in organisation's environment we should also use approaches better suited to conditions of turbulences and unpredicted changes. This kind of approaches are based on AI methods, knowledge management and knowledge technologies. In this conditions, evaluation systems should be based on knowledge and project stakeholders' needs and expectations. Modelling should be supported by chosen system approaches, concepts connected with knowledge management and methodology of management sciences. The principle of primacy of learning process over static use of knowledge resources should be engaged.

Modelling evaluation systems need to be aware of complex, multidimensional and turbulent reality. The one of the most important things about solving evaluation problems is their quality nature. Quantitative methods are less taken into consideration. It is needed to search for qualitative computer methods based on knowledge, modern mathematical instruments

\footnotetext{
${ }^{23}$ Grzeszczyk T.A. - Evaluation of European Projects 2007-
} 2013. Placet, Warszawa 2009 (in polish). 
and algorithms for discovering rules in the collections of data which are referring to project stakeholders.

Applied algorithms and computer methods in a model of project evaluation system should enable to take various, quantitative and qualitative evaluation criteria into account.

Evaluation criteria may refer to economic, social, environmental, legal and other aspects. According to that, modelled evaluation system should include different types of evaluation criteria. It provides an opportunity to evaluate various types of projects, which are related to specific criteria. Evaluation system's flexibility in the selection of different evaluation criteria means universality of the developed solutions. This versatility may also be associated with the suitability of the system for use in formative and summative evaluation processes.

Among many general assumptions of project evaluation system the following foundations should be considered as the most important ones. This system is an universal evaluation tool of different kinds of projects and ease of modification of the range and kind of executed evaluation process. In modelling process the multidisciplinary system approach to project evaluation is used. Evaluation system should make it possible to analyse surveys conducted among project stakeholders. It should ensure easy implementation taking criteria desirable by the system user into consideration. The system ought to provide possibility of using quantitative and qualitative evaluation criteria. Modelled evaluation system should include quantitative and qualitative results of project stakeholders' analysis.

In the evaluation process, we can often notice the lack of well-defined knowledge, which would provide perfectly reliable fundamentals for solving a decision problem. The designed solutions should provide solving evaluation problems even if data is unsuitable for solving a problem with classical statistical methods. Evaluation system needs to work properly with uncertain, incomplete and inconsistent input data. It is essential to ensure possibility of using different statistical, data mining and AI methods. Evaluation system ought to provide clear graphic visualisation of the project evaluation results.

Proposed project evaluation approach supported by association rule base is shown in Figure 4. The first step is to conduct surveys with project stakeholders. In the next stage data preprocessing is made, the aim of this is to adjust available survey results to the computer system. According to the assumptions adopted earlier, it is essential to ensure a possibility of using different statistical, data mining and AI methods. In order to limit study area, it was decided to use data mining algorithm for generating association rules.

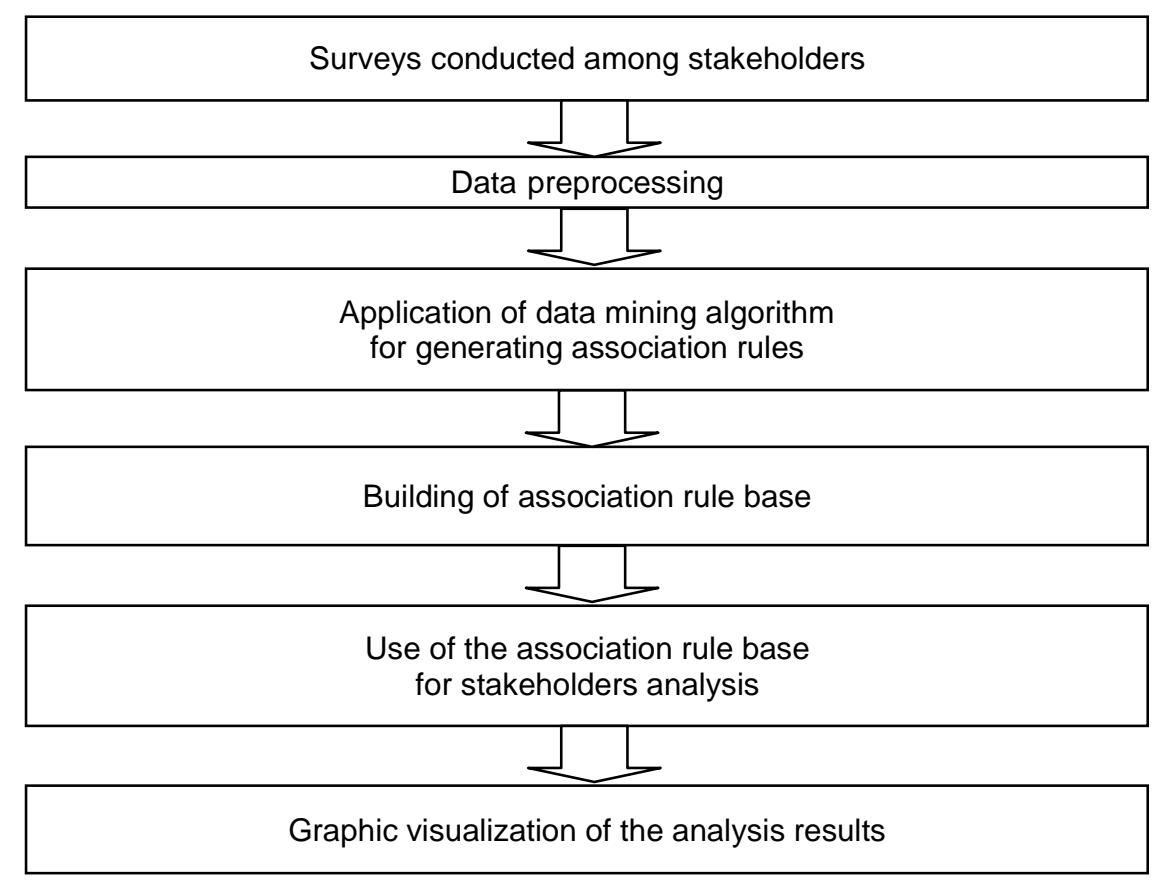

Figure 4. Proposed project evaluation approach (source: own study) 
The results which are the effect of computer calculations are the foundation for building association rule base. The software works in accordance with adopted algorithm. Then, we can use this base in the stakeholder analysis process. The last stage of the proposed project evaluation approach is graphic visualisation of the analysis results. This graphical visualisation makes it easier to interpret the results and increases the practical utility of this evaluation system.

The evaluation system concept has led to the realisation of an exemplary implementation of this kind of system. Experiments results are shown in the next section of this paper.

\section{The example of using association rule base for project stakeholders analysis}

The example of evaluation system based on knowledge refers to building knowledge-base useful in the stakeholder analysis process. This type of analysis was selected because of its great importance in project evaluation practise.

Surveys which are conducted among stakeholders are used in the empirical verification of proposed project evaluation approach. Interviewees are potentially associated with the public project for the protection of local community health. Survey was carried out among stakeholders from the Podlaskie Voivodeship (mainly from the area of the town of Lomza). In the study, there are included 150 records in data set. The results from this research should not be considered as representative sample of entire population. The data is hypothetical and helpful in illustrating only the proposed system.

In accordance with previously formulated concept of a new evaluation system based on knowledge, such empirical research may be performed in the following steps. In order to conduct surveys among project stakeholders, it is recommended to (if possible) precisely define community from which stakeholders come from. Evaluators should also prepare a set of questions in the questionnaires addressed to them. The most comfortable questionnaires are in the electronic version. It is possible to send them to all respondents. These surveys provide data for further processing using the selected data mining algorithm.

According to the conception formulated in the previous section of this paper, the next step is data preprocessing. After completing this step, the results of the survey are useful for processing by a computer pro- gramme which is in accordance with the algorithm for generating association rules. Exemplary implementation of the project evaluation system was realised with the use of software StatSoftStatistica 10.

Opinions on public health services were researched in the following scale:

$$
\begin{aligned}
& \text { 1-Poor } \\
& 2 \text { - Fair } \\
& 3 \text { - Good } \\
& 4 \text { - Excellent }
\end{aligned}
$$

The survey included five most pressing local health problems:

$$
\begin{aligned}
& 1 \text { - Alcohol abuse, } \\
& 2 \text {-Cancer, } \\
& 3 \text {-Depression, } \\
& 4 \text { - Obesity, } \\
& 5 \text { - Smoking. }
\end{aligned}
$$

Three following barriers to health improvement were taken into account:

$$
\begin{aligned}
& \text { 1-MTE - Medication Too Expensive, } \\
& \text { 2-DAS - Difficult Access to Specialists, } \\
& 3 \text { - TAP - Toxic Air Pollution. }
\end{aligned}
$$

Hereafter presented the analysis results of the five most pressing local health problems. These problems are recorded in the data file as multiple response variables. That was five possible answers from which project stakeholders have to choose.

Gender saved such us dichotomy variable - dichotomous data: Male and Female. From the data file made rules about associations. For identifying these rules uses the a-priori algorithm ${ }^{24}$.This algorithm required a user-defined threshold values for process of rule generation - minimum: support, confidence and correlation. Assume the following values:

- support $-30 \%$,

- confidence $-70 \%$,

- correlation $-50 \%$.

Basing on calculations with using data mining software author has built association rule base, which has, afterwards, used for stakeholders analysis. The results of this analysis are available in at least two forms: legible association rules and graphic visualisation.

24 The a-priori algorithm is implemented in Statistica software.Agrawal R., Srikant R. - Fast Algorithms for Mining Association Rules [at] International Conference Proceedings. VLDB'94 - Very Large Data Bases. Morgan Kaufmann, California 1994, pp. 487-499. 


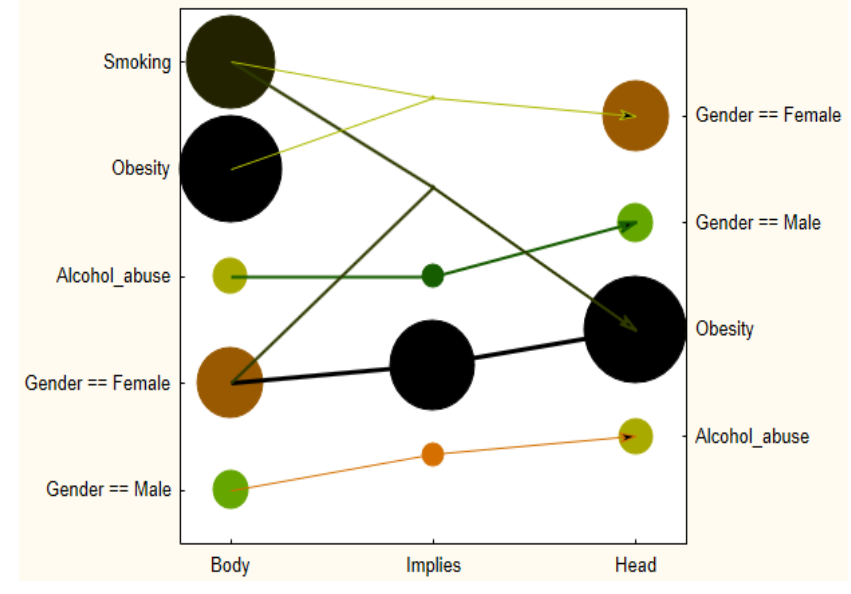

Figure 5. Association rules network (source: own study)
Figure 5 presents this kind of graphic visualisation (2D version). Visualization confirms the practical utility of the proposed solutions.

The major association rules are shown in Table 1 . On the basis of the analysis of these rules useful conclusions can be drawn. For example, men living in the local area see mostly alcohol abuse problem and women - obesity. With the problem being noticed by women, associates second health risks. It is smoking. This kind of women response may have been probably the result of generalised opinion that quitting smoking causes weight gain.

Table 1. Summary of association rules

(source: own study)

\begin{tabular}{|c|c|c|c|c|}
\hline & If Body then Head & $\begin{array}{c}\text { Support } \\
{[\%]}\end{array}$ & $\begin{array}{c}\text { Confidence } \\
{[\%]}\end{array}$ & $\begin{array}{c}\text { Correlation } \\
{[\%]}\end{array}$ \\
\hline 1 & If Gender = Male then Alcohol abuse & 34.67 & 78.79 & 79.39 \\
\hline 2 & If Gender = Female then Obesity & 48.00 & 85.71 & 76.67 \\
\hline 3 & If Alcohol abuse then Gender = Male & 34.67 & 80.00 & 79.39 \\
\hline 4 & If Gender = Female and Smoking then Obesity & 30.67 & 82.14 & 59.99 \\
\hline 5 & Obesity and Smoking then Gender = Female & 30.67 & 74.19 & 63.74 \\
\hline
\end{tabular}

The results obtained in the form of legible association rules and graphic visualization can provide a reliable basis, e.g. for the evaluation of conformity accomplished health protection programs to the needs of the local community. They are also useful in development of strategies based on the identified health needs, initial stages of defining public programs objectives and programs priorities formulating. Later proposed projects which solve chosen problems may be better suited to the residents' of the local communities real health needs.

\section{Summary and conclusions}

The presented example of knowledge-base for project evaluation has turned to be useful in practical applications. As a result of computer calculations, results were obtained in two forms: readable association rules and graphic visualization. They are simple to understand and interpret. Easy to formulate conclusions result from rules and they can be additionally illustrated thanks to 2D and 3D graphic visualizations.

Solutions proposed in this study may seem to be complicated for evaluators without technical education.
But they are not. Complex data mining algorithms are available in quite a simple way. There is no need to require extensive knowledge in ICT technology from members of evaluation team carrying out this kind of stakeholders analysis. Working with software used to calculations and analysis is intuitive, and necessary defining of parameters is limited to minimum.

Research which is carried out currently refer to the author's previous works looking for new evaluation methods whose creation results from development of new ITC technologies. These researches are based on inspirations resulting from a present state of knowledge in modern management theories and practises. Using systems thinking enables development of evaluation systems toward comprehensive solutions. New project evaluation methods based on knowledge together with classical approaches can be found useful in the modelling process of a comprehensive evaluation system.

On the basis of knowledge methods which enable to increase the number of evaluation methods used in comprehensive evaluation systems. They can be used to solve problems which are difficult to apply in classi- 
cal evaluation methods. These methods are very suitable to solve reasoning problems under the conditions of uncertainty. Empirical data are usually uncertain, blurred and fuzzy. That is why it is difficult to present them in a numeric form.

Empirical information and knowledge can be unreliable, imprecise and incomplete. Methods based on a strict and precise mathematical description of a complex project situation have lesser and lesser significance in the evaluation process. Thus, these phenomena are, most of all, of a qualitative character. In this context one has great hopes of conducting interdisciplinary research on application of selected new ICT technologies and AI methods in comprehensive evaluation.

Research results, which are connected with formulating a concept, realising experimental implementation and verifying the solution proposed in this article are promising. These researches should require to be continued. It is necessary to work out theoretical basis of a model of evaluation system and formulate its formalised definition. This formalised description enables to formulate next experimental model implementations and further practical research connected with applications of proposed solutions.

\section{$7 \quad$ References}

[1] Barrows E., Neely A. - Managing Performance in Turbulent Times: Analytics and Insight. John Wiley \& Sons, Hoboken, New Jersay 2012.

[2] Damm D., Schindler M. - Security issues of a knowledge medium for distributed project work [in] International Journal of Project Management, 20 (2002).

[3] Grzeszczyk T.A. - Application of Neural Networks for Prior Appraisal of Structural Funds Project Proposals [in] Seruca I., Filipe J., Hammoudi S., Cordeiro J. (ed.) - Enterprise Information Systems, Vol. 2. Portucalense University, Porto, Portugal 2004.

[4] Grzeszczyk T.A. - Application of the Rough Set Method for Evaluation of Structural Funds Projects [in] Manolopoulos Y., Filipe J., Constantopoulos P., Cordeiro J. (ed.) - Artificial Intelligence and Decision Support Systems. Paphos, Cyprus 2006.

[5] Grzeszczyk T.A. - Modeling Evaluation of European Projects. Placet, Warszawa 2012 (in polish).

[6] Grzeszczyk T.A. - Evaluation of European Projects 2007-2013. Placet, Warszawa 2009 (in polish).
[7] Grzeszczyk T.A. - Towards the Model of Comprehensive Project Evaluation System [in] Monographic Series of Faculty of Management, ed. T. Krupa, Warsaw University of Technology, Warsaw 2013.

[8] Heldman K. - PMP. Project Management Professional Exam. Study guide. John Wiley \& Sons, Inc., Indianapolis 2011.

[9] Kisielnicki J. - Project Management. People procedures - results. Wolters Kluwer Business, Warsaw 2011 (in polish).

[10] Liebowitz J. - Conceptualizing and implementing knowledge management [in] Love P., Fong P., Irani Z. (eds.) - Management of Knowledge in Project Environments. Routledge, 2005.

[11] Love P., Fong P., Irani Z. (eds.) - Management of Knowledge in Project Environments, Routledge, 2005.

[12] MEANS Collection, Vol. 1 - Evaluating socioeconomic programmes [in] Evaluation design and management. European Commission Structural Funds, Luxembourg 1999.

[13] Patton M.Q. - Qualitative Research \& Evaluation Methods. SAGE Publications, Inc., Thousand Oaks, London, New Delhi 2002.

[14] PMBOK Guide - A Guide to the Project Management Body of Knowledge, Fourth Edition [in] Management Training \& Development Center. Warszawa 2009.

[15] Rossi P.H., Lipsey M.W., Freeman H. E., Evaluation - A Systematic Approach. Thousand Oaks, Sage Publications, Inc., CA 2004.

[16] Scriven M. - Evaluation thesaurus. Sage Publications, Inc., London 1991.

[17] Agrawal R., Srikant R. - Fast Algorithms for Mining Association Rules [in] International Conference Proceedings. VLDB'94 - Very Large Data Bases, Morgan Kaufmann, California 1994, pp. 487-499.

[18] Stefanowicz B. - Algorithms. Heuristics. Analogies [in] Statistical News, 3/2012 (in polish).

[19] Trocki M., Bukłaha E., Grucza B. - Projects and Project Management Knowledge Management in Projects [in] Methodologies, Models of Competence and Maturity Models (ed.) Trocki M. Publishing House Warsaw School of Economics, Warsaw 2011 (in polish).

[20] Wyrozębski P - Study of Project Knowledge Management Practices in Polish Organizations [in] Wyrozębski P., Juchniewicz M., Metelski W. Knowledge, Maturity and Risk in Project Management. Publishing House Warsaw School of Economics, Warsaw 2012 (in polish). 